\title{
Mechanical quantitative sensory testing in cavalier King Charles spaniels with and without syringomyelia
}

\author{
Ashley C. Hechler, Eric T. Hostnik, Laurie B. Cook, Lynette K. Cole and Sarah A. Moore*
}

\begin{abstract}
Background: Syringomyelia (SM) is a debilitating condition in the cavalier King Charles spaniel (CKCS) that results in neuropathic pain and diminished quality of life. Von Frey aesthesiometry (VFA) is a method of mechanical quantitative sensory testing that provides an objective sensory threshold (ST) value and can be used to quantify neuropathic pain (NP) and monitor response to therapy. The utility of VFA has been previously established in client-owned dogs with acute spinal cord injury but the technique has not been evaluated in dogs with SM. The goal of this study was to evaluate ST, as determined by VFA, in dogs with and without SM, to assess the utility of VFA in quantifying NP in SMaffected dogs. We hypothesized the SM-affected CKCS would have lower ST values, consistent with hyperesthesia, when compared to control CKCS. Additionally, we hypothesized that ST values in SM-affected dogs would be inversely correlated with syrinx size on MRI and with owner-derived clinical sign scores.

Results: ST values for the thoracic and pelvic limbs differed significantly between the SM-affected and control CKCS $(p=0.027 ; p=0.0396$ respectively). Median ST value (range) for the thoracic limbs was $184.1 \mathrm{~g}$ (120.9-552) for control dogs, and $139.9 \mathrm{~g}$ (52.6-250.9) for SM-affected dogs. The median ST value (range) for the pelvic limbs was $164.9 \mathrm{~g}$ (100.8-260.3) in control dogs and $129.8 \mathrm{~g}(57.95-168.4)$ in SM-affected dogs. The ST values in SM-affected dogs did not correlate with syrinx height on MRI $(r=0.314 ; p=0.137)$. Owner-reported clinical sign scores showed an inverse correlation with pelvic limb ST values, where dogs with lower ST values (hyperesthesia) were reported by their owners to display more frequent and severe clinical signs $(r=-0.657 ; p=0.022)$.

Conclusion: ST values were lower in SM-affected CKCS compared to control dogs, suggesting the presence of neuropathic pain. Dogs with lower ST pelvic limb values were perceived by their owners to have more severe clinical signs classically associated with SM. Our results suggest that VFA might offer quantitative assessment of neuropathic pain in SM-affected dogs and could be useful for monitoring response to therapy in future clinical studies.
\end{abstract}

Keywords: Chiari-like malformation, Syringomyelia, Neuropathic pain, Quantitative sensory testing, von Frey aesthesiometry, Cavalier King Charles spaniel

\footnotetext{
* Correspondence: moore.2204@osu.edu

The Ohio State University Veterinary Medical Center, 601 Vernon L. Tharp

Street, Columbus, $\mathrm{OH} 43221$, USA
}

(c) The Author(s). 2020 Open Access This article is licensed under a Creative Commons Attribution 4.0 International License, which permits use, sharing, adaptation, distribution and reproduction in any medium or format, as long as you give appropriate credit to the original author(s) and the source, provide a link to the Creative Commons licence, and indicate if changes were made. The images or other third party material in this article are included in the article's Creative Commons licence, unless indicated otherwise in a credit line to the material. If material is not included in the article's Creative Commons licence and your intended use is not permitted by statutory regulation or exceeds the permitted use, you will need to obtain permission directly from the copyright holder. To view a copy of this licence, visit http://creativecommons.org/licenses/by/4.0/. The Creative Commons Public Domain Dedication waiver (http://creativecommons.org/publicdomain/zero/1.0/) applies to the data made available in this article, unless otherwise stated in a credit line to the data. 


\section{Background}

Syringomyelia (SM) is an acquired neurologic disorder that can result in debilitating pain in the cavalier King Charles spaniel (CKCS) breed. SM is the development of fluid-filled cavitations in the cervical, thoracic, and occasionally lumbar spinal cord [1, 2], most often affecting the dorsal horn, resulting in presumptive abnormalities of sensory processing due to disruption of the normal pathways. In CKCS, SM results secondary to a malformation of the skull termed Chiari-like malformation(CM), both of which are diagnosed using magnetic resonance imaging (MRI). Clinical signs of SM include an array of behaviors such as compulsive scratching of the neck and flank, unprovoked vocalizations, and apparent sensitivity to light touch [1,3-8]. While these clinical signs have long been suspected to represent behavioral manifestations of neuropathic pain, studies using quantitative measures of sensation to document a neuropathic pain state in SM-affected dogs are limited [9].

In addition to being a disease of substantial importance within the CKCS breed, SM-affected dogs may represent an important clinical animal model through which to study new interventions aimed at treating neuropathic pain (NP). A canine clinical model of neuropathic pain would complement existing experimental laboratory animal models by offering the ability to study a naturally occurring disease, in a clinical setting, with canine patients who are diagnosed and managed in a similar fashion to people with the same disease. Of equal importance, developing objective measures of NP in dogs with SM might allow more targeted studies of medical and surgical interventions aimed at improving outcome in affected canine patients and their human counterparts. Von Frey aesthesiometry (VFA) is a non-invasive, mechanical quantitative sensory test that delivers a known amount of punctate pressure to a body region until a behavioral manifestation of pain is elicited. The value obtained is termed the sensory threshold and alterations in this number can detect the presence of hyperesthesia and hypoesthesia [10, 11]. Hyperesthesia, encompassing both allodynia and hyperalgesia, is a common manifestation of neuropathic pain in people (14). Von Frey Aesthesiometry is used in people and laboratory rats to measure punctate hyperesthesia mediated through $A \delta$-fibers as a representative value for the severity of neuropathic pain resulting from central sensitization [10-12].

The goal of the present study was to conduct an investigation of mechanical quantitative sensory testing (QST), a technique for measuring neuropathic pain, using VFA in CKCS with and without SM. The primary aim was to identify the presence of hyperesthesia in SM-affected dogs manifested by lower sensory threshold (ST) values compared to control dogs. A secondary aim was to evaluate the association between VFA-acquired ST values and severity of SM as documented on magnetic resonance imaging (MRI), and via a previously validated owner-derived score of clinical signs using a questionnaire specifically designed for CKCS with SM [6]. We hypothesized that dogs with SM would have significantly lower ST values than dogs without SM, consistent with hyperesthesia. We also hypothesized that ST values in SM-affected dogs would be inversely correlated with MRI severity of SM and with severity of owner-reported clinical signs of SM.

Table 1 Demographic factors (age, sex) for 29 CKCS with and without syringomyelia (SM)

\begin{tabular}{|c|c|c|c|c|}
\hline Patient & Age (years) & Sex & CM Grade & SM Grade \\
\hline \multicolumn{5}{|l|}{ Control } \\
\hline 1 & 1.5 & $\mathrm{MN}$ & 1 & 0 \\
\hline 2 & 1 & $\mathrm{Fl}$ & 2 & 0 \\
\hline 3 & 1.5 & $\mathrm{MN}$ & 1 & 0 \\
\hline 4 & 1.5 & FS & 1 & 0 \\
\hline 5 & 1.5 & $\mathrm{Ml}$ & 1 & 0 \\
\hline 6 & 1 & $\mathrm{Ml}$ & 2 & 0 \\
\hline 7 & 1.5 & $\mathrm{MN}$ & 2 & 0 \\
\hline 8 & 1 & $\mathrm{Fl}$ & 1 & 0 \\
\hline 9 & 2 & $\mathrm{MN}$ & 1 & 0 \\
\hline 10 & 1 & $\mathrm{MN}$ & 1 & 0 \\
\hline \multicolumn{5}{|c|}{ SM-Affected } \\
\hline 1 & 5 & $\mathrm{MN}$ & 2 & 1 \\
\hline 2 & 8 & FS & 2 & 2 \\
\hline 3 & 7 & $\mathrm{MN}$ & 2 & 2 \\
\hline 4 & 5 & FS & 2 & 2 \\
\hline 5 & 8 & FS & 2 & 2 \\
\hline 6 & 6 & FS & 2 & 2 \\
\hline 7 & 6 & $\mathrm{MN}$ & 1 & 2 \\
\hline 8 & 6 & $\mathrm{MN}$ & 1 & 2 \\
\hline 9 & 4 & $\mathrm{MN}$ & 2 & 2 \\
\hline 10 & 3 & $\mathrm{MN}$ & 1 & 1 \\
\hline 11 & 1.5 & $\mathrm{Fl}$ & 1 & 1 \\
\hline 12 & 1.5 & $\mathrm{FI}$ & 1 & 1 \\
\hline 13 & 1.5 & $\mathrm{Ml}$ & 2 & 2 \\
\hline 14 & 1.5 & $\mathrm{Fl}$ & 1 & 2 \\
\hline 15 & 1 & FS & 2 & 2 \\
\hline 16 & 5 & FS & 2 & 2 \\
\hline 17 & 3 & FS & 2 & 2 \\
\hline 18 & 1 & FS & 2 & 1 \\
\hline 19 & 1 & $\mathrm{Ml}$ & 2 & 2 \\
\hline
\end{tabular}

CM Chiari-like malformation, SM Syringomyelia, MI, Intact male, MN Neutered male, FI Intact female, FS Spayed female 


\section{Results}

\section{Case selection}

Nineteen SM-affected and 10 control CKCS were prospectively enrolled from a population of 46. Demographic factors (age, sex) for all dogs included in the present study are summarized in Table 1 and enrollment process is summarized in a CONSORT flow diagram (Supplementary Material). Control dogs ranged from 1 to 2 years of age (median 1.5 years) and SM-affected dogs ranged from 1 to 8 years of age (median 4 years). SM-affected dogs were significantly older than control

Table 2 MRI findings for 10 control and 19 syringomyelia (SM)affected CKCS

\begin{tabular}{|c|c|c|}
\hline Patient & PSOM & SM Height (mm) \\
\hline \multicolumn{3}{|l|}{ Control } \\
\hline 1 & $\mathrm{~N}$ & - \\
\hline 2 & $\mathrm{~N}$ & - \\
\hline 3 & $\mathrm{~N}$ & - \\
\hline 4 & $L$ & - \\
\hline 5 & B & - \\
\hline 6 & N & - \\
\hline 7 & $\mathrm{~N}$ & - \\
\hline 8 & N & - \\
\hline 9 & L & - \\
\hline 10 & $\mathrm{~N}$ & - \\
\hline \multicolumn{3}{|c|}{ SM-Affected } \\
\hline 1 & $\mathrm{~N}$ & 1.119 \\
\hline 2 & $\mathrm{~N}$ & 6.028 \\
\hline 3 & L & 4.585 \\
\hline 4 & $\mathrm{R}$ & 4.94 \\
\hline 5 & $\mathrm{R}$ & 9.26 \\
\hline 6 & $\mathrm{~N}$ & 3.537 \\
\hline 7 & $\mathrm{~N}$ & 3.059 \\
\hline 8 & $\mathrm{~N}$ & 2.2125 \\
\hline 9 & $\mathrm{~N}$ & 2.438 \\
\hline 10 & $\mathrm{R}$ & 0.875 \\
\hline 11 & $N$ & 0.933 \\
\hline 12 & B & 1.422 \\
\hline 13 & N & 2.755 \\
\hline 14 & $\mathrm{R}$ & 2.689 \\
\hline 15 & $\mathrm{~N}$ & 3.748 \\
\hline 16 & B & 3.2 \\
\hline 17 & $\mathrm{~N}$ & 4.212 \\
\hline 18 & $\mathrm{R}$ & 1.726 \\
\hline 19 & $\mathrm{R}$ & 4.668 \\
\hline
\end{tabular}

$B$ Bilateral, $L$ Left, $N$ Normal, PSOM Primary secretory otitis media, $R$ Right, SM Syringomyelia dogs $(p=0.037)$, but the sex did not differ significantly between groups.

\section{Magnetic resonance imaging findings}

Individual MRI findings for control and SM-affected dogs are summarized in Table 2. Ten dogs had no evidence of SM and served as control dogs, while 19 dogs had evidence of SM on MRI and were termed "SM-affected". Using the BVA SM grading scale [13] to further delineate the severity of syringes on MRI, a diagnosis of grade $1 \mathrm{SM}$ (SM1) was present in 5 dogs and grade 2 SM (SM2) in 14 dogs. The syrinx height ranged from 0.87 to $1.7 \mathrm{~mm}$ (median $1.2 \mathrm{~mm}$ ) in SM1 dogs, and 2.2 to $9.26 \mathrm{~mm}$ (median $3.6 \mathrm{~mm}$ ) in SM2 dogs.

\section{Mechanical quantitative sensory testing}

The median sensory threshold (ST) value for the thoracic limbs was $184.1 \mathrm{~g}$ (range 120.9-552) in control dogs, and $139.9 \mathrm{~g}$ (range 52.6-250.9) in SM-affected dogs. The median ST value (range) for the pelvic limbs was $164.9 \mathrm{~g}(100.8-260.3)$ in control dogs and $129.8 \mathrm{~g}$ (57.95-168.4) in SM-affected dogs. ST values were significantly lower in the thoracic limbs $(p=0.027)$ and pelvic limbs $(p=0.039)$ of SM-affected dogs when compared to controls (Fig. 1a and b). There were no adverse effects secondary to VFA testing.

\section{Owner-derived clinical signs scores}

Using a previously validated questionnaire to assess owner perception of SM-associated clinical signs [6], SM-affected dogs were assigned a composite score for the severity of clinical signs obtained by averaging the frequency of an assortment of behaviors across several categories. Results for individual animals are summarized in Table 3. This information was available only for SM-affected dogs enrolled in the study on or after January 1, $2017(n=10)$. The median owner-derived composite clinical signs score for SM-affected dogs was 1.3 (SM- affected range 0.5-1.8), a clinically normal dog would receive a score of 0 .

\section{Sensory threshold values and syrinx size}

When SM-affected dogs were grouped by BVA grade, the median ST value for the thoracic limbs was $104.6 \mathrm{~g}$ (range 93-250.9) for the SM1 dogs and 142.8 g (range 49.9-178.9) for the SM2 dogs. In the pelvic limbs, the median ST value was 121.1 g (46-148.3) for SM1 dogs and $114.4 \mathrm{~g}$ (58-171.2) for SM2 dogs. There was no significant difference in thoracic or pelvic limb ST values between SM1 and SM2 dogs $(p=0.75$ and $p=0.89$, respectively; Fig. 2). The association between ST value and syrinx height, in millimeters, was evaluated for dogs with SM2. There was not a significant correlation between 


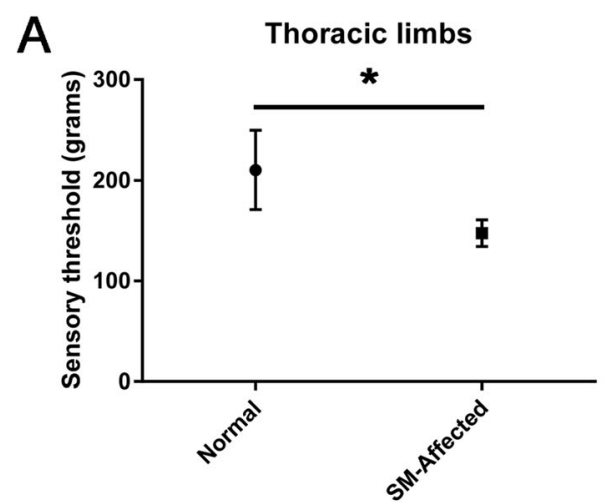

B

Pelvic limbs

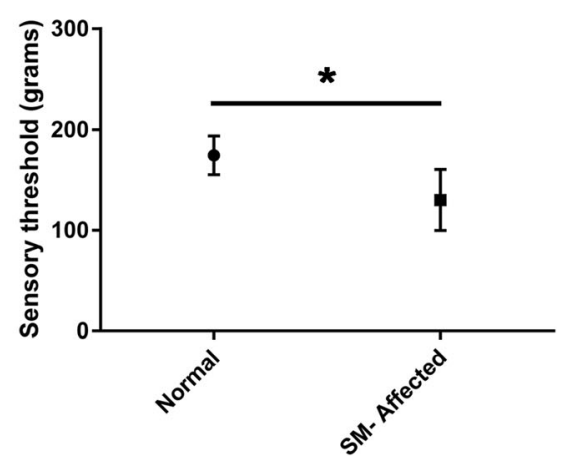

Fig. 1 Comparison of median and range sensory threshold (ST) values for thoracic (a) and pelvic (b) limbs in control and SM-affected CKCS. ST values are significantly lower in the thoracic and pelvic limbs of SM-affected dogs compared to controls, consistent with hyperesthesia and a neuropathic pain phenotype $\left(^{*}\right.$ denotes $\left.p<0.05\right)$

syrinx height and thoracic $(p=0.137)$ or pelvic limb $(p=$ 0.324) ST values.

\section{ST values and owner-derived SM clinical sign scores}

The relationship between owner-derived clinical sign scores and ST values was evaluated for all dogs where this information was available $(n=10$; Fig. 3$)$. A significant inverse correlation was observed between ST values and owner-reported clinical signs for the pelvic limbs $(r=-0.657 ; p=0.022)$, but not the thoracic limbs $(r=-$ $0.347 ; p=0.16$ ).

\section{Discussion}

Results of the present study suggest that thoracic and pelvic limb ST values, as measured by VFA, differ between control and SM-affected dogs. SM-affected dogs display lower ST values consistent with a neuropathic pain phenotype. This is not an unexpected finding, as hyperesthesia secondary to central sensitization has long been implicated as the cause of clinical signs in SM-affected dogs; however, this has not previously been quantified. In people, mechanical QST techniques such as VFA are classically used to detect the presence of allodynia. Allodynia can be further classified as dynamic, punctate, or static depending on the type of stimulus that elicits the sensation. Static allodynia, the less commonly recognized form, is typically restricted to the affected area and can be tested using superficial and deep pressure. Punctate allodynia, mediated by A $\delta$-fibers, most often follows a dermatomal pattern of distribution and is evaluated with von Frey monofilaments or pins [14]. Therefore, ability to identify allodynia relies heavily on the appropriate selection of diagnostic test and body region evaluated. Our study exclusively looked at punctate allodynia by using VFA to test dermatomal patterns commonly affected in SM [15]. The differences in location and prevalence of punctate and static allodynia may explain why our findings differ from another

Table 3 Owner-derived clinical sign scores for 10 syringomyelia (SM)-affected CKCS enrolled on or after January 1, 2017. Patient number corresponds to the number listed in Tables 1 and 2

\begin{tabular}{|c|c|c|c|c|c|c|c|c|c|c|}
\hline Patient & 10 & 11 & 12 & 13 & 14 & 15 & 16 & 17 & 18 & 19 \\
\hline Compulsive scratching & 2 & 4 & 4 & 3 & 3 & 3 & 3 & 2 & 3 & 2 \\
\hline Facial rubbing & 1 & 1 & 3 & 3 & 3 & 3 & 4 & 1 & 2 & 2 \\
\hline Hypersensitivity to light touch & 2 & 0 & 4 & 3 & 3 & 2 & 1 & 3 & 2 & 0 \\
\hline Unexplained yelping & 3 & 0 & 2 & 0 & 2 & 1 & 4 & 0 & 2 & 1 \\
\hline Not willing to lift head & 2 & 0 & 1 & 1 & 1 & 0 & 1 & 0 & 2 & 1 \\
\hline Not willing to bend neck to eat & 2 & 0 & 1 & 0 & 0 & 0 & 1 & 0 & 2 & 0 \\
\hline Weakness or ataxia & 2 & 0 & 0 & 0 & 0 & 0 & 0 & 1 & 2 & 0 \\
\hline Strange behaviors & 1 & 0 & 0 & 0 & 0 & 0 & 0 & 0 & 0 & 0 \\
\hline Reluctance to defecate & 0 & 0 & 0 & 0 & 0 & 0 & 0 & 0 & 0 & 0 \\
\hline Sleep with head elevated & 1 & 0 & 0 & 2 & 2 & 0 & 0 & 0 & 3 & 2 \\
\hline Composite Score & 1.6 & 0.5 & 1.5 & 1.2 & 1.4 & 0.9 & 1.4 & 0.7 & 1.8 & 0.8 \\
\hline
\end{tabular}

0: never; 1: seldom, 2: sometimes; 3 : usually; 4: always 

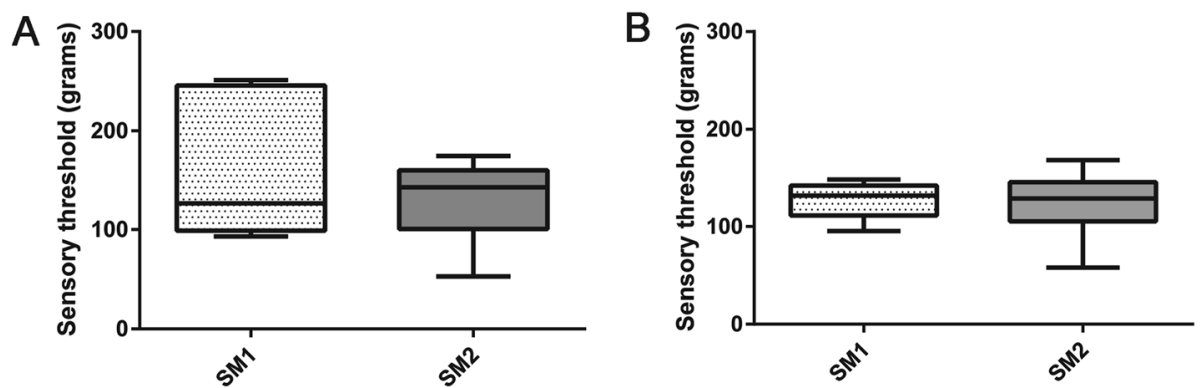

Fig. 2 Comparison of median and range sensory threshold (ST) values for thoracic (a) and pelvic (b) limbs in SM1 and SM2-affected CKCS. There is no significant difference in thoracic or pelvic limb ST between SM1 and SM2-affected dogs $(P>0.05$ in all cases)

recent study [9] which did not identify a difference in ST values or thermal latencies in CKCS with and without SM. Sparks et al. used hemostatic forceps to apply pressure to the subcutaneous tissues of the neck and thoracic limbs, exclusively evaluating static allodynia [9]. Static allodynia is less frequently reported in people with neuropathic pain, and when reported tend to affect small areas which may be difficult to map in affected dogs [14]. Additionally, several SMaffected dogs in the Sparks et al. study received analgesics immediately prior to the testing procedures. Previous studies have documented increased ST values following analgesic administration [16]. Our study required a one-week washout of all medications prior to enrollment; therefore, eliminating the confounding effect of analgesics on ST values.

The presence of a neuropathic pain phenotype in SMaffected dogs, as documented by VFA, is further supported by the identification of a significant inverse correlation between owner-reported severity of clinical signs and ST values, where SM-affected dogs with lower pelvic limb ST values displayed a higher frequency and severity of clinical behaviors commonly associated with

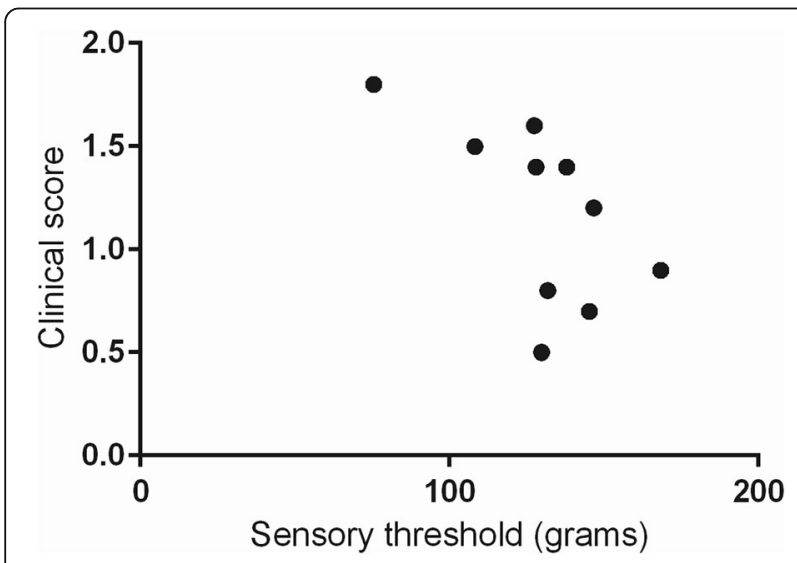

Fig. 3 Relationship between sensory threshold (ST) values for pelvic limbs and owner-derived clinical sign scores for SM-affected dogs $(n=10)$. There is a significant inverse correlation between pelvic limb ST values and clinical signs, suggesting that animals with more pronounced hyperesthesia showed more clinical signs of SM at home $(r=-0.657 ; p=0.022)$ neuropathic pain. Interestingly, this relationship did not hold true for the thoracic limbs. Of consideration here may be the difference between at-level and below-level pain. Immediately following an injury affecting the nerve roots or spinal cord, at-level pain develops in the dermatomes of the affected spinal cord segment which may resolve over time [17]. Below-level pain develops later from central sensitization, affecting dermatomes caudal to the site of injury [18], and has been associated with higher pain scores than at-level neuropathic pain in people [19]. Below-level pain can persist longer and is often more difficult to treat [20], mirroring the clinical course for some SM-affected dogs who can be quite refractory to analgesics. It is possible that many of the pain-related questions, asked of owners to derive a clinical signs score, focus more on manifestations of belowlevel pain (for example, hypersensitivity to light touch, where some of our dogs scored the highest). Alternatively, our small sample size may have created difficulty in identifying a statistical relationship given the higher variability in the thoracic limb ST dataset for SMaffected dogs. Because only 10 dogs without SM were able to be recruited for the study, it is possible that our lack of ability to establish differences may represent a Type II statistical error and that study in a larger population of animals may be warranted. It is important to note this study only included images of the cervical and cranial thoracic spinal cord, so it is possible a portion of the population had multifocal or holocord syringomyelia which would contribute to the distribution of pain.

An unexpected finding in the present study was the lack of relationship between ST values in SM-affected dogs and syrinx height observed on MRI or difference between SM grades using the BVA scheme. While some studies suggest that syrinx size predicts severity of neuropathic pain-related clinical signs, there is conflicting evidence regarding this relationship in the human and veterinary literature $[3,7,9,21,22]$. Recently, the focus in human and veterinary medicine has shifted from assessing the size of the syrinx to evaluating the symmetry, with asymmetrical syringes more commonly 
associated with neuropathic pain [3, 7, 23, 24]. Alternatively, our study may have been underpowered to detect these differences, given the small group size. Due to the small number of dogs included in this study, we were unable to assess the effect of asymmetry on ST values; however, this represents an important avenue for future studies. An additional consideration in the present study is that most SM-affected dogs were graded SM2, with only five SM1 dogs included. The small number of SM1 dogs may have confounded our ability to identify a statistically significant difference in ST values between mild and more severely SM-affected dogs.

An important limitation in our study, and one that begs discussion for all CM/SM studies in CKCS, is the difficulty in identifying a true "normal" population for comparison within the breed. While the importance of $\mathrm{CM}$ as a contributor to pain has been historically minimized in dogs with SM, it has been documented in both people and dogs to cause pain in the absence of SM [9, 25-27], with or without variable contribution from concurrent craniocervical junction anomalies [28-30]. Selection of CKCS without CM or other minor occipital or skull-based malformations proves near impossible due to the ubiquitous nature of these malformations within the breed $[7,31]$. Indeed $100 \%$ of the control population in the present study had CM apparent on MRI. Therefore, it is impossible to determine from the present study the degree to which CM alone influences ST values; however, its universal presence in both the control and SMaffected groups suggests that SM is likely the driver of significant differences between the two groups. The commonality of primary secretory otitis media (PSOM) [31] in the breed provides another potential confounder, although PSOM-affected dogs do not always display signs indicative of discomfort $[32,33]$. In this study, we attempted to exclude patients with PSOM by requiring otoscopic examination by a board-certified veterinary dermatologist showing a normal appearance of the tympanic membrane prior to enrolling. However, the sensitivity of otoscopic examination for a diagnosis of PSOM is low [33] and several SM-affected dogs had evidence of PSOM on MRI. Because normal CKCS used in the present study were recruited from another, unrelated trial, the potential also exists that some degree of selection bias may have been present in the control population that could influence the documented changes between groups.

\section{Conclusion}

VFA is a non-invasive test that can be used to document the presence of neuropathic pain. In the current study, ST values were lower in SM-affected dogs compared to controls, indicating hyperesthesia which is suggestive of a neuropathic pain phenotype. Additionally, ST pelvic limb values were inversely correlated with owner-reported severity of clinical signs suggesting that hyperesthetic dogs displayed more frequent and severe clinical signs of SM. While ST values did not correlate with imaging severity of SM as assessed using syrinx size, additional studies are needed to assess the relationship between other imaging parameters such as asymmetry of syringes and results of mechanical QST. Future studies should focus on the effect of medical and surgical interventions on ST values in SMaffected dogs and should work to define the influence on ST values of other common comorbidities of the head and cervical spine in CKCS.

\section{Methods}

Client-owned CKCS enrolled in the current study were presented to OSU Veterinary Medical Center between June 2010 and June 2018. In total, twenty-nine dogs were enrolled; 10 cavalier King Charles spaniels (CKCS) free of imaging characteristics of SM and 19 CKCS with SM documented on MRI. Sample size determinations were based on pilot data from seven normal and five SM-affected CKCS. The results suggested 15 dogs per group were necessary to detect a $50 \%$ difference between normal and SM-affected ST with $90 \%$ power and alpha = 0.05 . Dogs were included if they were greater than 1 year of age, were cardiovascularly stable for general anesthesia, and were free of significant dermatologic or otologic disease as determined by a board-certified veterinary dermatologist (LKC) on physical and dermatologic examination. Dogs were excluded if the tympanic membrane was bulging on otoscopic examination, if they had any evidence of concurrent neurologic or dermatologic disease on physical examination, or if separation anxiety prevented diagnostic work-up. Dogs less than 2 years of age had a PCV/TS, while the remainder had complete blood counts and biochemistry profiles suggesting general good health. At the completion of the study, all dogs were discharged and returned to their owners.

\section{Control dogs $(n=10)$}

Ten apparently healthy CKCS were recruited from a population of 29 dogs presenting to The Ohio State University Veterinary Medical Center Dermatology Service (LKC) for an unrelated study. While our sample size calculation originally suggested that at least 15 dogs per group would be required, enrollment was truncated at 10 due to challenges with identifying dogs without SM on MRI and the eventual conclusion of the unrelated study. Dogs were free of significant abnormalities on a complete neurological examination performed by one of the investigators (SAM), and free of dermatologic and otologic disease as assessed by a board-certified veterinary dermatologist (LKC), and had not received any medications in the 7 days prior to study enrollment. All dogs were 
Table 4 Chiari malformation (CM) and syringomyelia (SM) severity scoring strategy, as proposed by the British Veterinary Association (BVA) for use in stratifying dogs with CM/SM [13]

\begin{tabular}{ll}
\hline Grade & CM \\
\hline CM0 & $\begin{array}{l}\text { Cerebellum is rounded with CSF between vermis and foramen } \\
\text { magnum }\end{array}$ \\
CM1 $\begin{array}{l}\text { Indentation of cerebellum by supraoccipital bone; CSF present } \\
\text { between vermis and foramen magnum }\end{array}$ \\
CM2 Cerebellar vermis is impacted into or through the foramen \\
magnum
\end{tabular}

assigned a CM grade and classified by a single radiologist (ETH) as having no evidence of SM based on MRI of the brain and cervical spine (SM0 using the British Veterinary Association (BVA) scale; Table 4). The radiologist was blinded to the clinical information and VFA results of each patient.

\section{Affected dogs $(n=19)$}

SM-affected CKCS were recruited from a population of 46 dogs presenting to the OSU Veterinary Medical Center Dermatology and Neurology services (LKC or ACH). All dogs underwent a complete dermatologic and neurologic examination performed by one of the investigators (SAM, LKC, ACH). A radiologist (ETH), blinded to clinical status and VFA results, assigned a BVA grade for both CM and SM. The dogs were classified as "SM-affected" based on the presence of imaging characteristics consistent with SM (BVA SM grade 1 or 2) on MRI of the brain and cervical spine (Table 4) [13]. Dogs were not administered any medications in the 7 days prior to study enrollment.

\section{Questionnaire $(n=10)$}

Owners of SM-affected dogs completed a clinical signs questionnaire previously developed as a semi-quantitative measure of quality of life, neurobehavioral changes and owner perceived pain scores in SM-affected CKCS $(n=10)[6,34]$. The questionnaire asked owners to assign a severity score for 10 questions addressing clinical signs based on a 5-point Likert-type rating scale (behavior happens $0=$ never, $1=$ seldom, $2=$ sometimes, $3=$ usually, $4=$ always) $[6,34]$. Frequency scores for each clinical behavior were averaged across categories to provide a single clinical sign score for each dog, resulting in a maximum potential score of 5 .

\section{Von Frey Anesthesiometry}

Mechanical QST of all four limbs was performed using an electronic von Frey anesthesiometer (VFA-
IITC Life Science; Woodlands, CA) in a method previously described by our laboratory $[35,36]$. Limb test order was determined at random after dogs were allowed 15 minutes to acclimate to the investigators. Dogs were prevented from visualizing the device during application to ensure behavioral responses were due to tactile stimulation [37]. The minimum force, in grams, required to elicit a behavioral response (attempt to escape, eye movements, lip licking, vocalization) was recorded five times per leg, with a 1-min break between testing to avoid windup, ST decay, and hypersensitization [37-39]. The highest and lowest ST values obtained from each limb were discarded and the middle three values were averaged to produce a mean ST value per limb for each dog. Immediate withdrawal of the limb without pressure or conscious response was determined to be a reflexive movement and was discarded and the stimulus was repeated after 1 minute [13, 37, 40]. All measurements were made by the same investigator (SAM), who was unaware of SM status at the time of examination and was blinded to owner-reported behavior history.

\section{Magnetic resonance imaging}

An MRI of the brain and cervical spine was performed under general anesthesia in all dogs $(n=29)$. All anesthetic protocols were customized for the individual patient by a board-certified veterinary anesthesiologist or anesthesia resident. The protocols included an intravenous pre-medication and maintenance on isoflurane. Dogs were imaged in dorsal recumbency using a 3.0 Tesla Philips Achieva magnet or 3.0 Tesla Philips Ingenia model magnet (Highland Heights, $\mathrm{OH}$ 44143). At minimum, T1-weighted $\quad(\mathrm{TR}=450-700$ milliseconds; $\mathrm{TE}=8$ milliseconds $)$ and $\mathrm{T} 2$-weighted $(\mathrm{TR}=3500-5000$ milliseconds; $\mathrm{TE}=110$ milliseconds) images were obtained in the sagittal plane for review, with additional sequences and transverse images obtained on a case-bycase basis as medically indicated and dependent on presence and location of syringes.

Image interpretation was performed by a single boardcertified veterinary radiologist (ETH) blinded to patient clinical history and QST results. A commercially available DICOM viewing software program (Horos $2 \mathrm{k}$ v. 2.0.2, https://www.horosproject.org) was used to measure syrinx height (in millimeters), at the location of maximum apparent height, and to grade the $\mathrm{CM}$ in the sagittal plane. CM and SM grades were assigned using the BVA grading scheme depicted in Table 4 [13]. Concurrent presence or absence of imaging characteristics consistent with PSOM were recorded for each dog as normal, unilateral (denoted as left or right based on affected side), or bilateral [41]. 


\section{Statistical analysis -}

Age and sex were compared between groups using the Wilcoxin rank-sum test. To facilitate statistical comparisons, ST values for the limbs of each individual dog were averaged to produce a single mean ST value for the thoracic limbs and for the pelvic limbs. Summary data for ST in thoracic and pelvic limbs (g), syrinx height $(\mathrm{mm}), \mathrm{CM}$ and SM grade, and owner-derived clinical sign scores were reported using descriptive statistics. Data were evaluated for normality using the ShapiroWilks test and were reported as median (range) because the data were not normally distributed. The Wilcoxon rank-sum test was used to compare mean ST values between control and SM-affected dogs. Relationships between owner-derived composite clinical sign scores, imaging findings, and ST values were evaluated using Spearman correlations. Statistical analyses were performed using GraphPad Prism and $P \leq 0.05$ was considered significant for all tests.

\section{Supplementary information}

Supplementary information accompanies this paper at https://doi.org/10. 1186/s12917-020-02313-7.

Additional file 1. CONSORT flow diagram depicting the enrollment process.

\section{Abbreviations}

BVA: British veterinary association; CCJ: Craniocervical junction; CKCS: Cavalier King Charles spaniel; CM: Chiari-like malformation; CM1: Grade 1 Chiari-like malformation; CM2: Grade 2 Chiari-like malformation; CSF: Cerebrospinal fluid; MRI: Magnetic resonance imaging; NP: Neuropathic pain; PSOM: Primary secretory otitis media; QST: Quantitative sensory testing; SCl: Spinal cord injury; SM: Syringomyelia; SMO: Grade 0 syringomyelia; SM1: Grade 1 syringomyelia; SM2: Grade 2 syringomyelia; ST: Sensory threshold; VFA: Von frey anesthesiometry

\section{Acknowledgements}

The authors gratefully acknowledge Ms. Amanda Disher, Ms. Heather Anderson, Ms. Lane Bookenberger, and Ms. Josey Sobolewski for their assistance with patient care and data collection. This work was published in abstract form and presented in part at the American College of Veterinary Internal Medicine Forum 2019, Phoenix, AZ.

\section{Authors' contributions}

SAM developed the concept and design of the study. SAM and $\mathrm{ACH}$ performed data collection and statistical analysis and were the major contributors to the writing of the manuscript. SAM, ACH, and LBC were responsible for patient management during appointments. SAM obtained VFA measurements in all patients. LKC performed all dermatologic and otic examinations. ETH evaluated MRIs for diagnosis, measurements, and grading in all dogs. All authors were accountable for the accuracy and integrity of the work and participated in review of the manuscript. The author(s) read and approved the final manuscript.

\section{Funding}

This was funded by the Grey Lady Foundation, The Ohio State University Canine Research Funds NCATS UL1TR002733, The Ohio State University Canine Research Funds (Paladin) and American Cavalier King Charles Spaniel Charitable Fund. The funders had no role in the study design, execution, analyses, interpretation of the data, or manuscript preparation.

\section{Availability of data and materials}

The datasets used and/or analyzed during the current study are available from the corresponding author on reasonable request.

\section{Ethics approval and consent to participate}

This study was reviewed and approved by the Institutional Care and Use Committee and Clinical Research Advisory Committee of The Ohio State University (2010A00000140 and 2017 V15). Signed owner consent was obtained prior to enrollment of all cases,

\section{Consent for publication}

Not applicable.

\section{Competing interests}

The authors declare that they have no competing interests.

Received: 12 February 2019 Accepted: 11 March 2020

Published online: 20 March 2020

\section{References}

1. Rusbridge C, MacSweeny JE, Davies JV, Chandler K, Fitzmaurice SN, Dennis $\mathrm{R}$, et al. Syringohydromyelia in cavalier king Charles spaniels. J Am Anim Hosp Assoc. 2000;36(1):34-41.

2. Loderstedt S, Benigni L, Chandler K, Cardwell JM, Rusbridge C, Lamb CR, et al. Distribution of syringomyelia along the entire spinal cord in clinically affected cavalier king Charles spaniels. Vet J. 2011;190(3):359-63.

3. Rusbridge C, Carruthers H, Dubé M-P, Holmes M, Jeffery ND. Syringomyelia in cavalier King Charles spaniels: the relationship between syrinx dimensions and pain. J Small Anim Pract. Blackwell Publishing Ltd. 2007;48(8):432-6.

4. Rusbridge C, Jeffery ND. Pathophysiology and treatment of neuropathic pain associated with syringomyelia. Vet J. 2008;175(2):164-72.

5. Plessas IN, Rusbridge C, Driver CJ, Chandler KE, Craig A, McGonnell IM, et al. Long-term outcome of Cavalier King Charles spaniel dogs with clinical signs associated with Chiari-like malformation and syringomyelia. Vet Rec. British Medical Journal Publishing Group. 2012;171(20):501.

6. Rutherford L, Wessmann A, Rusbridge C, McGonnell IM, Abeyesinghe S, Burn C, et al. Questionnaire-based behaviour analysis of cavalier king Charles spaniels with neuropathic pain due to Chiari-like malformation and syringomyelia. Vet J. 2012;194(3):294-8.

7. Sparks CR, Cerda-Gonzalez S, Griffith EH, Lascelles BDX, Olby NJ. Questionnaire-based analysis of owner-reported scratching and pain signs in cavalier king Charles spaniels screened for Chiari-like malformation and Syringomyelia. J Vet Intern Med. 2017:50:37-9.

8. Hu HZ, Rusbridge C, Constantino-Casas F, Jeffery N. Distribution of substance $\mathrm{P}$ and calcitonin gene-related peptide in the spinal cord of cavalier king Charles spaniels affected by symptomatic syringomyelia. Res Vet Sci. 2012:93(1):318-20.

9. Sparks CR, Gorney A, Williams K, Griffith EH, Cerda-Gonzalez S, Lascelles BDX, et al. Investigation of sensory thresholds in cavalier king Charles spaniels with and without Chiari-like malformations and syringomyelia. J Vet Intern Med. 2018;50:37-8.

10. Rolke R, Magerl W, Andrews Campbell K, Schalber C, Caspari S, Birklein F, Treede RD. Quantitative sensory testing: a comprehensive protocol for clinical trials. Eur J Pain. 2006:10:77-88.

11. Choi Y, Yoon YW, Na HS, Kim SH, Chung JM. Behavioral signs of ongoing pain and cold allodynia in a rat model of neuropathic pain. Pain. 1994;59: 369-76

12. Woolf CJ. Central sensitization: implications for the diagnosis and treatment of pain. Pain. 2011;152(3 Suppl):S2-15.

13. Association BV. Chiari Malformation/ Syringomyelia Scheme. 2012. pp. 1-4.

14. Jensen TS, Finnerup NB. Allodynia and hyperalgesia in neuropathic pain: clinical manifestations and mechanisms. The Lancet Neurology Elsevier Ltd. 2014;13(9):924-35.

15. Hatem SM, Attal N, Ducreux D, Gautron M, Parker F, Plaghki L, et al. Clinical, functional and structural determinants of central pain in syringomyelia. Brain. 2010;133(11):3409-22.

16. KuKanich B, Lascelles BDX, Papich MG. Assessment of a von Frey device for evaluation of the antinociceptive effects of morphine and its application in pharmacodynamic modeling of morphine in dogs. Am J Vet Res. 2005;66(9): $1616-22$. 
17. Detloff MR, Wade RE Jr, Houlé JD. Chronic at- and below-level pain after moderate unilateral cervical spinal cord contusion in rats. J Neurotrauma. 2013;30(10):884-90.

18. Finnerup NB, Norrbrink C, Trok K, Piehl F, Johannesen IL, Sørensen JC, et al. Phenotypes and predictors of pain following traumatic spinal cord injury: a prospective study. J Pain Elsevier Ltd. 2014;15(1):40-8.

19. Landmann G, Berger MF, Stockinger L, Opsommer E. Usefulness of laserevoked potentials and quantitative sensory testing in the diagnosis of neuropathic spinal cord injury pain: a multiple case study. Nat Publishing Group. 2017;55(6):575-82.

20. Finnerup NB, Jensen TS. Spinal cord injury pain--mechanisms and treatment. Eur J Neurol. 2004;11(2):73-82.

21. Lu D, Lamb CR, Pfeiffer DU, Targett MP. Neurological signs and results of magnetic resonance imaging in 40 cavalier king Charles spaniels with Chiari type 1-like malformation. Vet Rec. 2003;153:260-3.

22. Grant R, Hadley DM, Macpherson P, Condon B, Patterson J, Bone I, et al. Syringomyelia: cyst measurement by magnetic resonance imaging and comparison with symptoms, signs and disability. J Neurol, Neurosurg Psychiatry. BMJ Publishing Group; 198. 50(8):1008-14.

23. Milhorat TH, Kotzen RM, Mu HT, Capocelli AL, Milhorat RH. Dysesthetic pain in patients with syringomyelia. Neurosurgery. 1996;38(5):940-7.

24. Todor DR, Mu HT, Milhorat TH. Pain and syringomyelia: a review. Neurosurg Focus. 2000;8(3):1-6.

25. Strayer A. Chiari I malformation: clinical presentation and management. J Neurosci Nurs. 2001;33(2):90-6.

26. Eisenstat DDR, Bernstein M, Fleming JFR, Vanderlinden RG, Schutz H. Chiari Malformation in Adults: A Review of 40 Cases. Can J Neurol Sci. Cambridge University Press. 2015;13(03):221-8.

27. Knowler SP, Cross C, Griffiths S, McFadyen AK, Jovanovik J, Tauro A, et al Use of Morphometric Mapping to Characterise Symptomatic Chiari-Like Malformation, Secondary Syringomyelia and Associated Brachycephaly in the Cavalier King Charles Spaniel. Wade C, editor. PLoS ONE. 2017;12(1): e0170315.

28. Cerda-Gonzalez S, Olby NJ, Griffith EH. Dorsal compressive Atlantoaxial bands and the Craniocervical junction syndrome: association with clinical signs and Syringomyelia in mature cavalier king Charles spaniels. J Vet Intern Med. 2015;29(3):887-92.

29. Cerda-Gonzalez S, Olby NJ, Griffith EH. Medullary position at the Craniocervical junction in mature cavalier king Charles spaniels: relationship with neurologic signs and Syringomyelia. J Vet Intern Med. 2015;29(3):882-6.

30. Cerda-Gonzalez S, Bibi KF, Gifford AT, Mudrak EL, Scrivani PV. Magnetic resonance imaging-based measures of atlas position: relationship to canine atlantooccipital overlapping, syringomyelia and clinical signs. Vet J Elsevier Ltd. 2016;209:133-8.

31. Wijnrocx K, Van Bruggen LWL, Eggelmeijer W, Noorman E, Jacques A, Buys $\mathrm{N}$, et al. Twelve years of chiari-like malformation and syringomyelia scanning in cavalier king Charles spaniels in the Netherlands: towards a more precise phenotype. PLoS One. 2017;12(9):e0184893.

32. Stern-Bertholtz W, Sjöström L, Håkanson NW. Primary secretory otitis media in the cavalier king Charles spaniel: a review of 61 cases. J Small Anim Pract. 2003;44(6):253-6.

33. Cole LK, Samii VF, Wagner SO, Rajala-Schultz PJ. Diagnosis of primary secretory otitis media in the cavalier king Charles spaniel. Vet Dermatol. 2015;26(6):459-66.

34. Hsu Y, Serpell JA. Development and validation of a questionnaire for measuring behavior and temperament traits in pet dogs. J Am Vet Med Assoc. 2003;223(9):1293-300.

35. Moore SA, Hettlich BF, Waln A. The use of an electronic von Frey device for evaluation of sensory threshold in neurologically normal dogs and those with acute spinal cord injury. Vet J. 2013;197(2):216-9.

36. Song RB, Basso DM, da Costa RC, Fisher LC, Mo X, Moore SA. Von Frey anesthesiometry to assess sensory impairment after acute spinal cord injury caused by thoracolumbar intervertebral disc extrusion in dogs. Vet $\mathrm{J}$. Elsevier Ltd. 2016;209(C):144-9.

37. Detloff MR, Clark LM, Hutchinson K, Kloos AD, Fisher LC, Basso DM. Validity of acute and chronic tactile sensory testing after spinal cord injury in rats. Exp Neurol. 2010;225(2):366-76.

38. KuKanich B, Lascelles BDX, Papich MG. Use of a von Frey device for evaluation of pharmacokinetics and pharmacodynamics of morphine after intravenous administration as an infusion or multiple doses in dogs. Am J Vet Res. 2005;66(11):1968-74.
39. Detloff MR, Fisher LC, Deibert RJ, Basso DM. Acute and chronic tactile sensory testing after spinal cord injury in rats. J Vis Exp. 2012;62:e3247.

40. Kloos AD, Fisher LC, Detloff MR, Hassenzahl DL, Basso DM. Stepwise motor and all-or-none sensory recovery is associated with nonlinear sparing after incremental spinal cord injury in rats. Exp Neurol. 2005;191(2):251-65.

41. Owen MC, Lamb CR, Lu D, Targett MP. Material in the middle ear of dogs having magnetic resonance imaging for investigation of neurologic signs. Vet Radiol Ultrasound. 2004;45(2):149-55.

\section{Publisher's Note}

Springer Nature remains neutral with regard to jurisdictional claims in published maps and institutional affiliations.
Ready to submit your research? Choose BMC and benefit from:

- fast, convenient online submission

- thorough peer review by experienced researchers in your field

- rapid publication on acceptance

- support for research data, including large and complex data types

- gold Open Access which fosters wider collaboration and increased citations

- maximum visibility for your research: over $100 \mathrm{M}$ website views per year

At BMC, research is always in progress.

Learn more biomedcentral.com/submissions 